\title{
Trend Analysis of Relatively Large Diatoms Which Appear in the Intensive Study Area of the Ariake Sea, Japan in Winter (2011-2015) based on Remote Sensing Satellite Data
}

\author{
Kohei Arai 1 \\ 1 Graduate School of Science and Engineering \\ Saga University, Saga City, Japan
}

\author{
Toshiya Katano 2 \\ 2Tokyo University of Marine Science and Technology \\ Tokyo Japan
}

\begin{abstract}
Behavior of relatively large size of diatoms which appear in the Ariake Sea areas, Japan in winter based on remote sensing satellite data is clarified. Through experiments with Terra and AQUA MODIS data derived chlorophyll-a concentration and truth data of chlorophyll-a concentration together with meteorological data and tidal data which are acquired for 5 years (winter 2011 to winter 2015), it is found that strong correlation between the chlorophyll-a concentration and tidal height changes. Also it is found that the relations between ocean wind speed and chlorophyll-a concentration. Meanwhile, there is a relatively high correlation between sunshine duration a day and chlorophyll-a concentration.
\end{abstract}

Keywords-chlorophyl-a concentration; red tide; diatom; sunshine duration; ocean winds; tidal effect

\section{INTRODUCTION}

The Ariake Sea is the largest productive area of Nori (Porphyra yezoensis1) in Japan. In winters of 2012 and 2013, a massive diatom bloom occurred in the Ariake Sea, Japan [1]. In case of above red tides, bloom causative was Eucampia zodiacus 2. This bloom has being occurred several coastal areas in Japan and is well reported by Nishikawa et al. for Harimanada sea areas [2]-[10]. Diatom blooms have recurrently occurred from late autumn to early spring in the coastal waters of western Japan, such as the Ariake Sea [11] and the Seto Inland Sea [12], where large scale "Nori" aquaculture occurs. Diatom blooms have caused the exhaustion of nutrients in the water column during the "Nori" harvest season. The resultant lack of nutrients has suppressed the growth of "Nori" and lowered the quality of "Nori" products due to bleaching with the damage of the order of billions of yen [3].

This bloom had been firstly developed at the eastern part of the Ariake Sea. However, as the field observation is timeconsuming, information on the developing process of the red tide, and horizontal distribution of the red tide has not yet been clarified in detail. To clarify the horizontal distribution of red tide, and its temporal change, remote sensing using satellite data is quite useful.

\footnotetext{
${ }^{1}$ http://en.wikipedia.org/wiki/Porphyra

${ }^{2}$ http://www.eos.ubc.ca/research/phytoplankton/diatoms/centric/eucampia/e_z odiacus.html
}

In particular in winter, almost every year, relatively large size of diatoms of Eucampia zodiacus appears in Ariake Sea areas. That is one of the causes for damage of Porphyra yezoensis. There is, therefore, a strong demand to prevent the damage from Nori farmers. Since 2007, Asteroplanus karianus appears in the Ariake Sea almost every year. In addition, Eucampia zodiacus appears in Ariake Sea since 2012. There is a strong demand on estimation of relatively large size of diatoms appearance, size and appearance mechanism).

In this paper, the chlorophyll-a concentration algorithm developed for MODIS $^{3}$ is firstly validated. Then apply the algorithm to MODIS data which are acquired at the Ariake Sea areas, Japan specifically. Then a trend analysis of chlorophyll-a concentration in winter in 2011 to 2015 is made. The major influencing factor of Eucampia zodiacus appearance is chlorophyll-a concentration. The other environmental factors, such as sea water temperature, northern wind for convection of sea water have to be considered. Also, the relations between tidal effects and chlorophyll-a concentration as well as between ocean wind speed and chlorophyll-a concentration together with between sunshine duration a day and chlorophyll-a concentration.

In the next section, the method and procedure of the experimental study is described followed by experimental data and estimated results. Then conclusion is described with some discussions.

\section{METHOD AND PROCEDURE}

\section{A. The Procedure}

The procedure of the experimental study is as follows,

1) Gather the truth data of chlorophyll-a concentration measured at the observation towers in the Ariake Sea areas together with the corresponding areas of MODIS derived chlorophyll-a concentration,

2) Gather the meteorological data which includes sunshine duration a day, ocean wind speed and direction, tidal heights,

\footnotetext{
${ }^{3}$ http://modis.gsfc.nasa.gov/
} 
3) Correlation analysis between the truth data and MODIS derived chlorophyll-a concentration as well as between geophysical parameters, ocean wind speed, sunshine duration a day, tidal heights and chlorophyll-a concentration is made.

\section{B. The Intensive Study Areas}

Fig. 1 shows the intensive study areas in the Ariake Sea area, Kyushu, Japan.

There are three observation tower points, TW, S, and A. TW is closely situated to the Saga Ariake Airport and is situated near the river mouth. On the other hand, A is situated most closely to the coastal area while $\mathrm{S}$ is situated in the middle point of the Ariake Sea width and is situated most far from the coastal areas and river mouths.

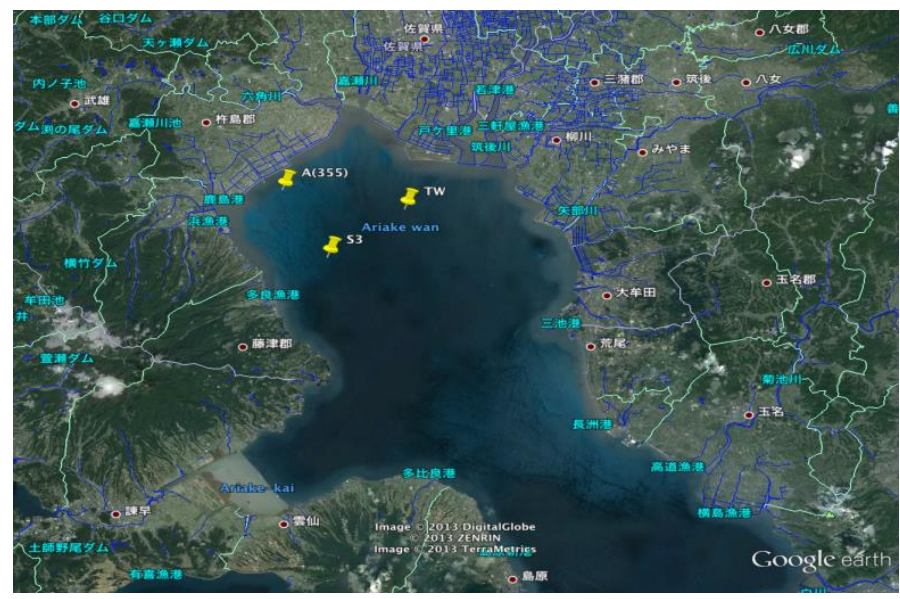

Fig. 1. Intensive study areas (Yellow pins shows the areas)

\section{EXPERIMENTS}

\section{A. The Data Used}

The truth data of chlorophyll-a concentration measured at the observation towers in the intensive study areas in the Ariake Sea areas together with the corresponding areas of MODIS derived chlorophyll-a concentration which area acquired for the observation period of one month during from January 1 to February 1 in 2011 to 2015 are used for the experiments. Also, the meteorological data which includes sunshine duration, ocean wind speed and direction, tidal heights which are acquired for the same time periods as MODIS acquisitions mentioned above. In particular for 2015, two months data are used for trend analysis.

Fig. 2 shows an example of the chlorophyll-a concentration image which is derived from MODIS data which is acquired on 2 March 2015. The chlorophyll-a concentration is measured at the tower, TW. This is red tide (Phytoplankton) blooming period. Such this MODIS derived chlorophyll-a concentration data are available almost every day except cloudy and rainy conditions.

Blooming is used to be occurred when the seawater becomes nutrient rich water, calm ocean winds, long sunshine duration after convection of seawater (vertical seawater current from the bottom to sea surface).

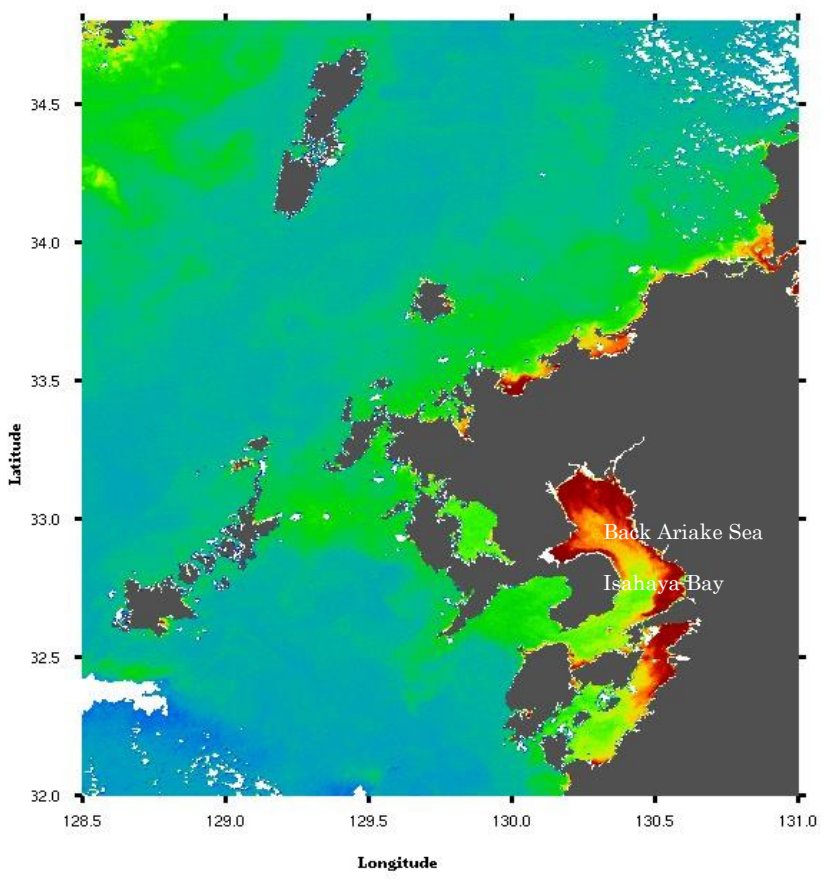

Fig. 2. Example of the chlorophyll-a concentration image which is derived from MODIS data which is acquired on 2 March 2015

Therefore, there must are relations between the geophysical parameters, ocean wind speed, sunshine duration, tidal heights and chlorophyll-a concentration. As shown in Fig.2, it is clear that the diatom appeared at the back in the Ariake Sea and is not flown from somewhere else. Also, there is relatively low chlorophyll-a concentration sea areas between Isahaya bay area and the back in the Ariake Sea area. Therefore, chlorophyll-a concentration variations are isolated each other (Isahaya bay area and the back in the Ariake Sea area).

\section{B. The Relation Between Truth Data and MODIS Derived Colorophyl-a Concentrations (Validation of the Algorithm for Chlorophyl-a Concentration Estimation)}

In order to validate the chlorophyll-a concentration estimation algorithm, the relation between truth data of Shipment data as well as Tower data and MODIS derived chlorophyll-a concentration is investigated. Before that, Tower data of chlorophyll-a concentration is compared to Shipment data. Fig. 3 shows the relation between these for intensive study area of TW. Also, Fig.4 shows relation of chlorophyll-a concentration between tower data and the other two of shipment data as well as MODIS data derived chlorophyll-a concentration. The time for data collection by ship is different from MODIS data acquisition time and tower data acquisition. Spatial resolutions of MODIS data derived Chlorophyll-a Concentration is $500 \mathrm{~m}^{2}$ while that of the shipment data and the tower data is just one point of data. Tower data is acquired every one hour. In the validation, averaged chlorophyll-a concentration a day is used because the shipment data acquisition time is varied and also MODIS data acquisition time is different by day by day. Therefore, relation between truth data and MODIS derived Chlorophyll-a Concentration is so scattered. 


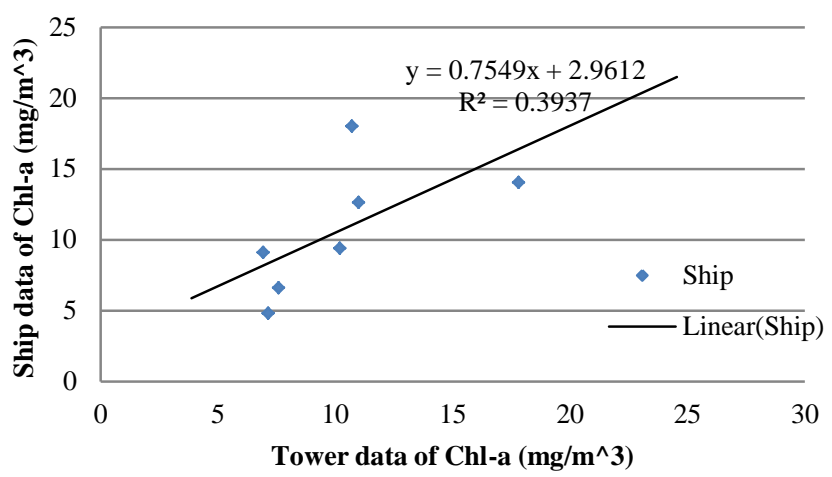

Fig. 3. Relation of the measured chlorophyll-a concentration between Tower data and Shipment data

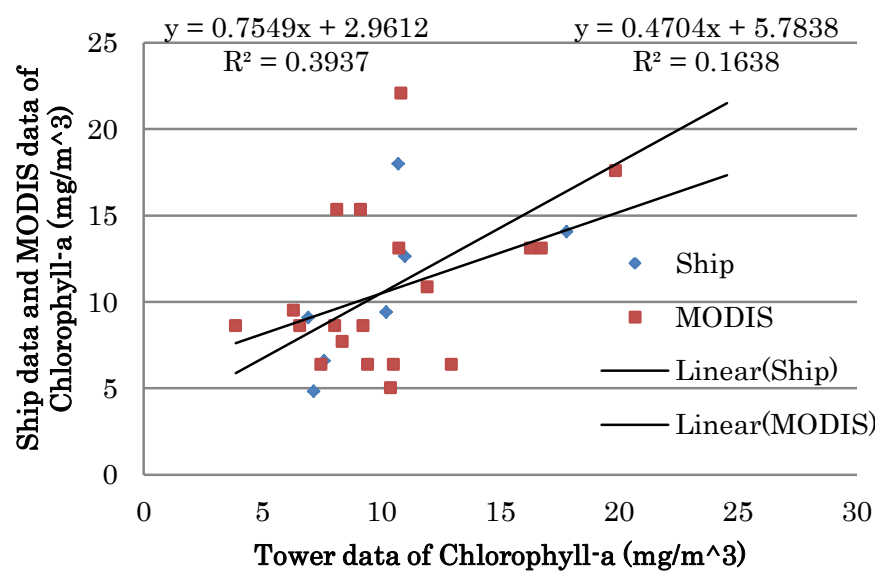

Fig. 4. Validation of Chlorophyll-a Concentration estimation algorithm

\section{Trend Analysis}

Fig.5 shows the trends of shipment data, tower data and MODIS derived chlorophyll-a concentrations measured in January to February in 2015. It seems that trends of MODIS, Tower, and Ship data derived chlorophyll-a concentration are similar. Also, it is found that high chlorophyll-a concentration is occurred on Spring tide while low chlorophyll-a concentration appears on neap time frames. Namely, the dates of neap of this time period are January 15, January 29, February 14 and February 28.

Meanwhile those of spring tide are January 7, January 23, February 7, February 21, and March 7. Chlorophyll-a concentration get up and down repeatedly on spring tides and neaps.

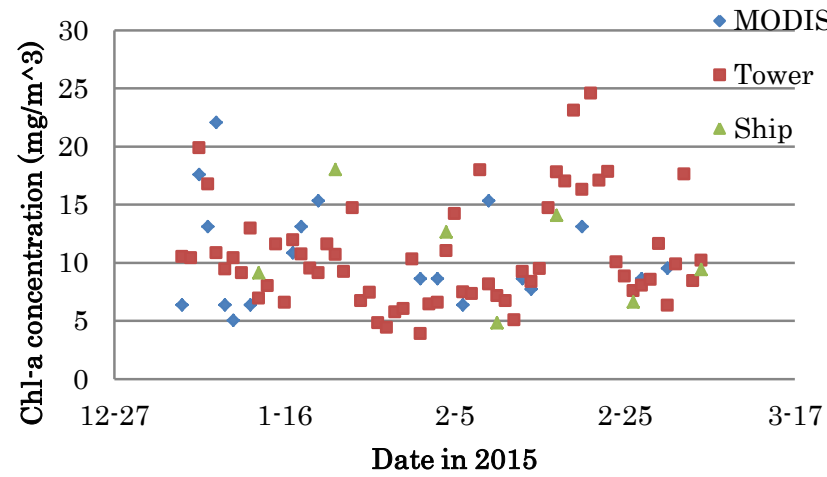

Fig. 5. Chlorophyll-a trend in January and February in 2015

On the other hand, Fig.6 (a) to (d) shows the results from trend analysis of chlorophyll-a concentrations in 2014, 2013, 2012, and 2011, respectively.

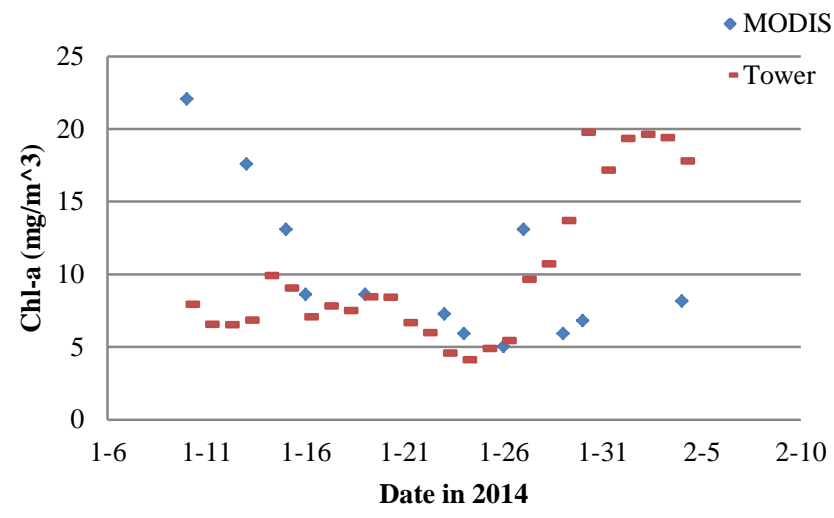

(a)January 2014

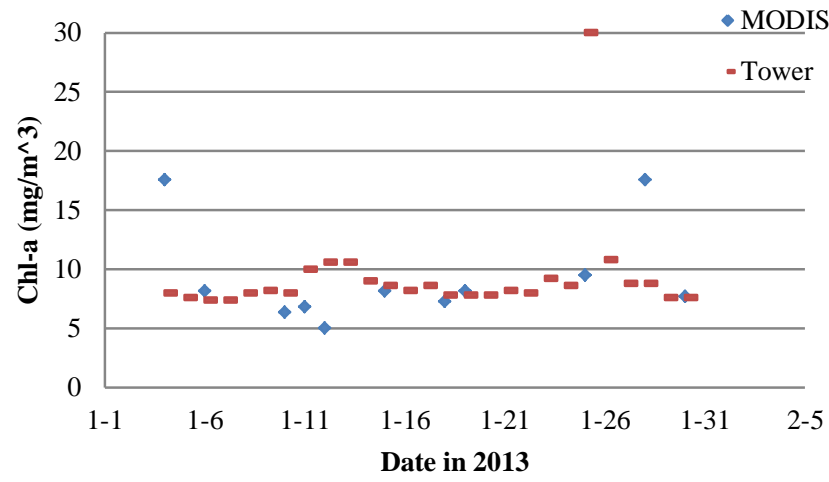

(b)January 2013 


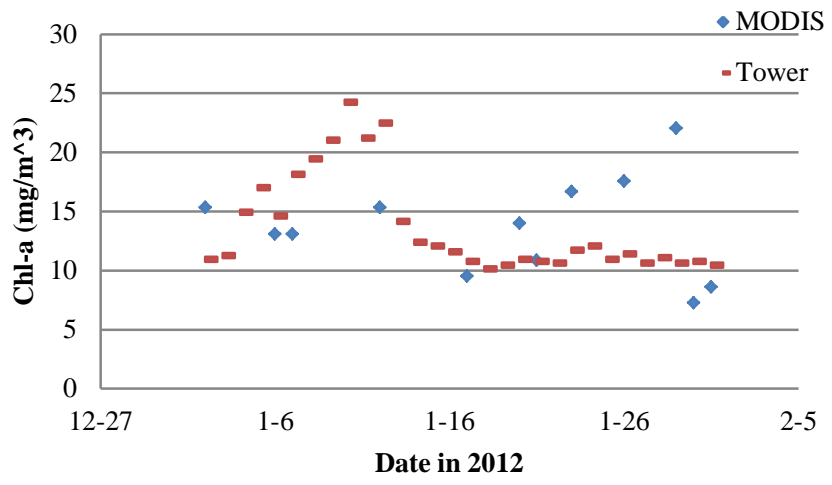

(c)January 2012

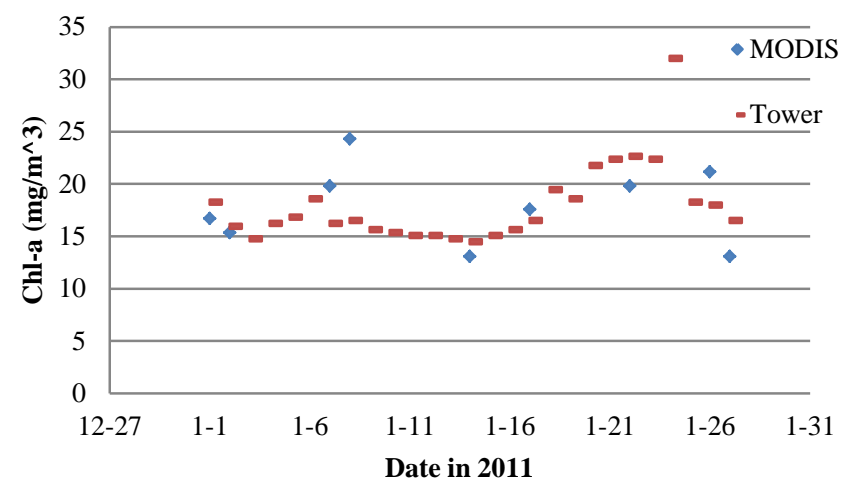

(d)January 2011

Fig. 6. Chlorophyll-a concentration trends in 2011 to 2014

Spring tides occurred on January 3, January 19 and February 2 while neaps appeared on January 10, and January 26 in 2014. Namely, chlorophyll-a concentration raised from January 26 and reached at the maximum on February 2.

It, however, is not always true. There is no peak at the spring tide on January 19 in the tower data derived chlorophyll-a concentration.

In 2013, the spring tides occurred on January 14 and January 30 while neaps appeared on January 7 and January 22, respectively. Tower data derived chlorophyll-a concentration shows the trend of the up and down of the concentration on sprig tides and neaps slightly. Meanwhile, the spring tides occurred on January 11, and January 25 while the neaps appeared on January 3, January 19 and February 2 in 2012, respectively. Although the tower data derived chlorophyll-a concentration shows the peak on January 11, there is no such peak on January 25 while the MODIS data derived chlorophyll-a concentration shows two peaks on January 11 and January 25. On the other hand, the spring tides occurred on January 6 and January 22 while the neaps appeared on January 14 and January 22, respectively. For both of the spring tide periods, both of MODIS data and tower data derived chlorophyll-a concentrations show the peaks and also show the valleys on the neaps. Therefore, it may conclude that there is strong relation between tide and chlorophyll-a concentration, it is not always true though.
In the neap period, vertical direction of sea water mixing due to tidal effect is not so large. Therefore, relatively large scale of diatoms moves to the sea bottom. Meantime, turbidity is getting down in neap period. Then the moved diatoms may be survived when transparency of sea water is getting up. After that, vertical direction of seawater mixing is occurred in spring tide period. Then the survived diatoms are getting up to sea surface. Thus blooming would occur if nutrition rich seawater is there.

\section{Relation Among Chlorophyll-a Concentration and Tidal \\ Height Difference a Day, Sun Shine Duration a Day, and Wind Speed from North}

Relation among chlorophyll-a concentration (Chl-a), tidal height difference a day, sun shine duration a day and wind speed from the north is clarified. Fig.7 shows the result.

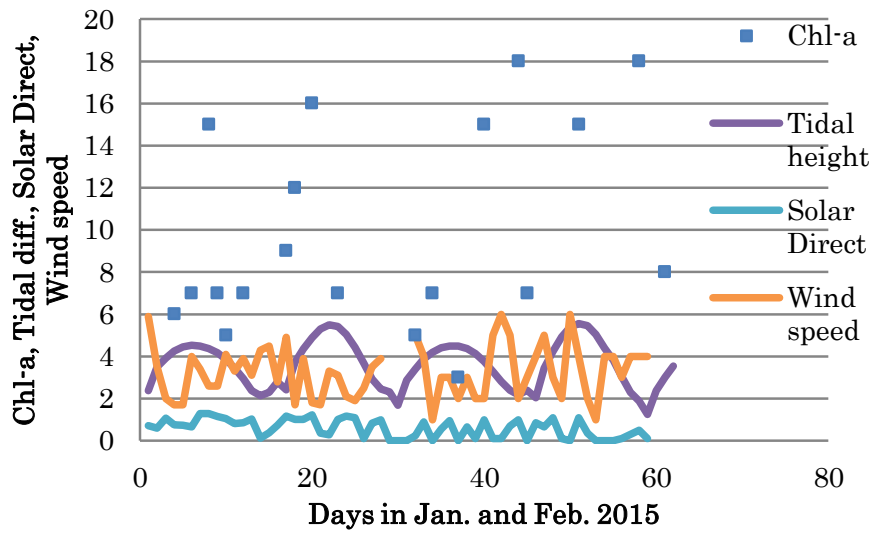

Fig. 7. Relation among chlorophyll-a, tidal height difference a day, sun shine duration a day and wind speed from the north

As shown in Fig.6, there is strong relation between tides and chlorophyll-a concentration. It, however, is not always true. Other factors, sun shine time duration a day is one of those as well as wind speed, in particular, north wind. In accordance with the other measured data of three dimensional chlorophyll-a as well as seawater temperature, salinity, Dissolved Oxygen: DO, turbidity, ph ratio, etc., it shows that poor oxygen water mass appears at the bottom of the sea and then it raised up to the sea surface (accordingly, chlorophyll-a rich seawater raised from the bottom of the sea and raised up to the sea surface). Wind speed helps to convection of the sea surface water while sun shine time duration helps to increase chlorophyll-a concentration in conjunction of warm up of the sea surface temperature.

These relations are almost same for the other year of chlorophyll-a concentration. Correlation coefficients are calculated between chlorophyll-a concentration and the other data of tidal difference a day, sun shine time duration a day and wind speed from the north. The result shows that there is a strong relation between chlorophyll-a concentration and tidal difference a day, obviously followed by wind speed from the north as shown in Fig.8.

It is not always true. The situation may change by year by year. In particular, there is clear difference between year of 2011 and the other years, 2012 to 2015. One of the specific reasons for this is due to the fact that chlorophyll-a 
concentration in 2011 is clearly greater than those of the other years. Therefore, clear relation between chlorophyll-a concentration and the other data of tidal difference a day, sun shine time duration a day and wind speed from the north cannot be seen. That is because of the fact that there is time delay of chlorophyll-a increasing after the nutrient rich bottom seawater is flown to the sea surface.

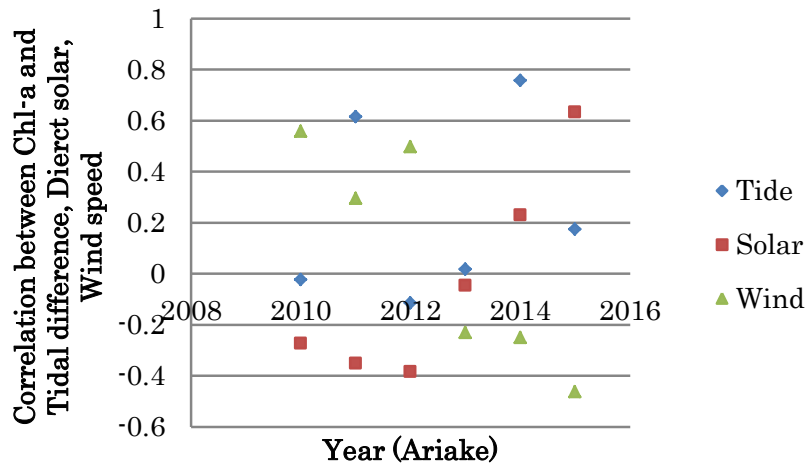

Fig. 8. Correlation coefficients between chlorophyll-a concentration and the other data of tidal difference a day, sun shine time duration a day and wind speed from the north

\section{CONCLUSION}

Behavior of relatively large size of diatoms which appear in the Ariake Sea areas, Japan in winter based on remote sensing satellite data is clarified. Through experiments with Terra and AQUA MODIS data derived chlorophyll-a concentration and truth data of chlorophyll-a concentration together with meteorological data and tidal data which are acquired for 5 years (winter 2011 to winter 2015), it is found that strong correlation between the chlorophyll-a concentration and tidal height changes. Also it is found that the relations between ocean wind speed and chlorophyll-a concentration. Meanwhile, there is a relatively high correlation between sunshine duration a day and chlorophyll-a concentration.

An analysis on phytoplankton distribution changes monitoring for the intensive study area of the Ariake Sea, Japan based on remote sensing satellite data is conducted. Phytoplankton distribution changes in the Ariake Sea areas, Japan based on remote sensing satellite data is studied. Through experiments with Terra and AQUA MODIS data derived chlorophyll-a concentration and truth data of chlorophyll-a concentration together with meteorological data and tidal data which are acquired in January in 2011 to 2015, it is found that strong correlation between the truth data of chlorophyll-a and MODIS derived chlorophyll-a concentrations with $\mathrm{R}$ square value ranges from 0.677 to 0.791 . Also it is found that the relations between ocean wind speed and chlorophyll-a concentration as well as between tidal difference a day and chlorophyll-a concentration. Meanwhile, there is a relatively high correlation between sunshine duration a day and chlorophyll-a concentration.

One of the knowledge raised from this study is the diatom appearance mechanism. The diatom appeared at the back in the Ariake Sea and is not flown from somewhere else. Also, there is relatively low chlorophyll-a concentration sea areas between Isahaya bay area and the back in the Ariake Sea area. Therefore, chlorophyll-a concentration variations are isolated each other (Isahaya bay area and the back in the Ariake Sea area).

Further study is required for clarification of

1) the difference between 2011 and the other years, 2012 to 2015 ,

2) the reason why it is not always true that chlorophyll-a concentration get high on the spring tide while that get low on the neap,

3) some other mechanism for diatoms appearance is clarified,

4) three dimensional measurements of seawater temperature, salinity, turbidity, DO, ph, and chlorophyll-a concentration have to be made,

5) nutrition rich water current from the river mouths has to be taken into account,

6) interaction between relatively large size of diatoms and the other red tide species has to be clarified and is taken into account on the appearance mechanism studies.

\section{ACKNOWLEDGMENT}

The authors would like to thank Dr. Yuichi Hayami, Dr. Kei Kimura, Kenji Yoshino, Naoki Fujii and Dr. Takaharu Hamada of Institute of Lowland and Marine Research, Saga University for their great supports through the experiments.

\section{REFERENCES}

[1] Yuji Ito, Toshiya Katano, Naoki Fujii, Masumi Koriyama, Kenji Yoshino, and Yuichi Hayami, Decreases in turbidity during neap tides initiate late winter large diatom blooms in a macrotidal embayment, Journal of Oceanography,69: 467-479. 2013.

[2] Nishikawa T (2002) Effects of temperature, salinity and irradiance on the growth of the diatom Eucampia zodiacus caused bleaching seaweed Porphyra isolated from Harima-Nada, Seto Inland Sea, Japan. Nippon Suisan Gakk 68: 356-361. (in Japanese with English abstract)

[3] Nishikawa T (2007) Occurrence of diatom blooms and damage tocultured Porphyra thalli by bleaching. Aquabiology 172: 405-410. (in Japanese with English abstract)

[4] Nishikawa T, Hori Y (2004) Effects of nitrogen, phosphorus and silicon on the growth of the diatom Eucampia zodiacus caused bleaching of seaweed Porphyra isolated from Harima-Nada, Seto Inland Sea, Japan. Nippon Suisan Gakk 70: 31-38. (in Japanese with English abstract)

[5] Nishikawa T, Hori Y, Nagai S, Miyahara K, Nakamura Y, Harada K, Tanda M, Manabe T, Tada K (2010) Nutrient and phytoplankton dynamics in Harima-Nada, eastern Seto Inland Sea, Japan during a 35year period from 1973 to 2007. Estuaries Coasts 33: 417-427.

[6] Nishikawa T, Hori Y, Tanida K, Imai I (2007) Population dynamics of the harmful diatom Eucampia zodiacus Ehrenberg causing bleachings of Porphyra thalli in aquaculture in Harima- Nada, the Seto Inland Sea, Japan. Harmful algae 6: 763-773.

[7] Nishikawa T, Miyahara K, Nagai S (2000) Effects of temperature and salinity on the growth of the giant diatom Coscinodiscus wailesii isolated from Harima-Nada, Seto Inland Sea, Japan. Nippon Suisan Gakk 66: 993-998. (in Japanese with English abstract)

[8] Nishikawa T, Tarutani K, Yamamoto T (2009) Nitrate and phosphate uptake kinetics of the harmful diatom Eucampia zodiacus Ehrenberg, a causative organism in the bleaching of aquacultured Porphyra thalii. Harmful algae 8: 513-517.

[9] Nishikawa T, Yamaguchi M (2006) Effect of temperature on lightlimited growth of the harmful diatom Eucampia zodiacus Ehrenberg, 
a causative organism in the discoloration of Porphyra thalli. Harmful Algae 5: 141-147.

[10] Nishikawa T, Yamaguchi M (2008) Effect of temperature on lightlimited growth of the harmful diatom Coscinodiscus wailesii, a causative organism in the bleaching of aquacultured Porphyra thalli. Harmful Algae 7: 561-566.

[11] Syutou T, Matsubara T, Kuno K (2009) Nutrient state and nori aquaculture in Ariake Bay. Aquabiology 181: 168-170. (in Japanese with English abstract)

[12] Harada K, Hori Y, Nishikawa T, Fujiwara T (2009) Relationship between cultured Porphyra and nutrients in Harima-Nada, eastern part of the Seto Inland Sea. Aquabiology 181: 146-149. (in Japanese with English abstract)

\section{AUTHORS PROFILE}

Kohei Arai, He received BS, MS and PhD degrees in 1972, 1974 and 1982, respectively. He was with The Institute for Industrial Science and Technology of the University of Tokyo from April 1974 to December 1978 also was with National Space Development Agency of Japan from January, 1979 to March, 1990. During from 1985 to 1987, he was with Canada Centre for Remote Sensing as a Post Doctoral Fellow of National Science and Engineering Research Council of Canada. He moved to Saga University as a Professor in Department of Information Science on April 1990. He was a councilor for the Aeronautics and Space related to the Technology Committee of the Ministry of Science and Technology during from 1998 to 2000 . He was a councilor of Saga University for 2002 and 2003. He also was an executive councilor for the Remote Sensing Society of Japan for 2003 to 2005 . He is an Adjunct Professor of University of Arizona, USA since 1998. He also is Vice Chairman of the Commission "A" of ICSU/COSPAR since 2008. He wrote 33 books and published 500 journal papers. He is now the Editor-in-Chief of IJACSA and IJISA. 